\title{
ENSINO, TECNOLOGIA E PRECONCEITO: DIÁRIO DE CAMPO EM UMA ESCOLA DESTINADA AO PÚBLICO LGBTTT NO BRASIL
}

\author{
ENSINO, TECNOLOGÍA Y PRECONCEITO: DIARIO DE CAMPO EN UNA \\ ESCUELA DESTINADA AL PÚBLICO LGBTTT EN BRASIL
}

\section{TEACHING, TECHNOLOGY AND PREJUDICE: FIELD DIARY IN A SCHOOL AIMED AT THE PUBLIC LGBTTT IN BRAZIL}

Renan Antônio SILVA ${ }^{1}$

\begin{abstract}
RESUMO: O Programa Federal Brasil "Sem Homofobia" foi lançado pela Secretaria Especial de Direitos Humanos (SEDH) em 2004, através do Conselho Nacional de Combate à Discriminação (CNCD). Este programa tem como objetivo combater a violência e a discriminação contra o grupo LGBT e promover cidadania homossexual, questionando temas relativos à homossexualidade em todos os Ministérios do Governo, além de propor políticas que apreciem esta população nas mais variadas esferas, entre elas a educação. No âmbito destas políticas, foi criada em Campinas-SP uma escola voltada para o público LGBTTT, chamada E-JOVEM. Desse modo, este artigo objetiva conhecer a realidade vivida pelos alunos e professores nessa referida escola e as possíveis transformações vividas tanto no âmbito pessoal (aprendizagem, liberdade, entre outros) quanto no âmbito coletivo, relativo ao combate à homofobia. Tais mudanças ou não, foram descritas em formato de diário de campo. Além da importância da escola na construção de uma sociedade que valorize a diversidade, o projeto $\mathrm{E}$ JOVEM contempla o uso das novas Tecnologias na Educação, tendo em vista o desenvolvimento de uma sociedade cada vez mais tecnológica e a consequente inserção dessas novas Tecnologias no processo de ensino aprendizagem. Os resultados preliminares apontam que afirmar-se gay ou lésbica é dizer, a princípio, que não viverá segundo o natural e o convencional, que irá experimentar uma forma nova de casamento e família, que não a esperada por pais, tios, avós, etc.
\end{abstract}

PALAVRAS-CHAVE: Escola. Inclusão. Tecnologia. Diário de campo.

RESUMEN: El Gobierno Federal del Programa "Sin Homofobia" fue lanzado por la Secretaría Especial de DERECHOS HUMANOS (SEDH) en 2004, utilizando el Consejo Nacional de Combate a la Discriminación (CNCD). Este programa TIENE combatir para la violencia y la discriminación contra el grupo LGBT y promover la ciudadanía homosexual, cuestionando cuestiones homosexuales en todos los ministerios del gobierno, proporcionados política. Además de que aprecien este NAS, la población varía MÁS áreas, incluyendo ELAS a la Educación. No D Esta área de política, la empleada fue Campinas-SP en una escuela orientada a la llamada pública o LGBTTT, E-JOVEN. De este modo a este conocer Artículo objetivo vivió Alumnos Realidad y Profesores En esta referida cabellera Posibilidades Transformaciones y vivas como no

${ }^{1}$ Universidade Estadual Paulista (Unesp), Faculdade de Ciências e Letras, Araraquara - SP - Brasil. Doutorando do Programa de Pós-Graduação em Educação Escolar. E-mail: lepp@rc.unesp.br 
muy Personal ámbito (aprendizaje, Libertad, Entre otros) colectivo Cuánto campo no en el año combate a la homofobia. Cambios no tales $O$, se describió el formato de diario de campo en. Además de la SIGNIFICACIÓN de la Escuela en la Construcción de la Sociedad Una valoración de la Diversidad, o Proyecto E-JOVEN contemplado o utilizado de las Nuevas Tecnologías en la Educación, Teniendo en vista o Desarrollo de la Sociedad MÁS cada vez más tecnológico y la consecuente Inserción de las Nuevas Tecnologías no Proceso de Aprendizaje. Los resultados preliminares apuntan a afirmar-es o gay lesbiana. Decir, un principio que no VIVERA segundo o natural, o convencional, ellos van a experimentar Una nueva forma de Boda y Familia que No esperaba por país, tíos, Abuelos, etc.

PALABRAS CLAVE: Escuela. Inclusión. Tecnología. Diario de campo.

ABSTRACT: The Brazilian Federal program "Without Homophobia" was launched by the Special Secretariat of Human Rights (SEDH) in 2004, through the National Council of Combating Discrimination (CNCD). This programme aims to combat violence and discrimination against the LGBT group and promote homosexual citizenship, questioning themes relating to homosexuality in all government ministries, and to propose policies that enjoy this population in the most varied spheres, among them education. In the context of these policies, it was created in Campinas-SP a school focused on the public LGBTTT, called E-Young. Thus, this article aims to know the reality experienced by the pupils and teachers in this school and the possible transformations experienced both in the personal sphere (learning, freedom, among others) as in the collective sphere, concerning combating homophobia. Such changes or not, have been described in field journal format. In addition to the importance of the school in building a society that values diversity, the E-young project contemplates the use of new technologies in education, with a view to developing an increasingly technological society and the consequent insertion of these new technologies in the learning process. The preliminary findings point out that stating whether gay or lesbian is to say, at first, that it will not live according to the natural and conventional, which is going to experience a new form of marriage and family, which is not expected by parents, uncles, grandparents, etc.

KEYWORDS: School. Inclusion. Technology. Field diary.

\section{Introdução}

O presente trabalho é fundamentado nas reflexões sobre homofobia e política (BORRILLO，2001; WELZER-LANG，2001; TIN，2008; SCHULMAN，2009) desenvolvida no campo das Ciências Humanas. Procura pensar, principalmente através das ferramentas teóricas e metodológicas da Antropologia e da História (LEGOFF, 1990; MAUSS, 1993; PORTELLI, 1996; EVANS-PRITCHARD, 2007), como as violências, toleradas pela população homossexual na escola, tornaram-se uma categoria 
de política pública no âmbito do Ministério da Educação do Governo Federal que lançou, em 2004, o Programa Federal "Brasil Sem Homofobia", pela Secretaria Especial de Direitos Humanos (SEDH), através do Conselho Nacional de Combate à Discriminação (CNCD). Tendo como subtítulo "Programa de Combate à Violência e à Discriminação contra GLBT e Promoção da Cidadania Homossexual”, propõe questionar temas relativos à homossexualidade em todos os Ministérios do Governo e requerer políticas que apreciem essa população nas mais variadas esferas, entre elas a educação.

Buscando sanar a problemática existente, o Governo Federal autorizou, em 2009, juntamente com o financiamento do Ministério da Cultura (MINC), a abertura da Escola E-JOVEM, voltada para o público gay do Brasil, instalada na cidade de Campinas, interior de São Paulo. A escola oferece aulas de Expressão Literária, Expressão Cênica, Espanhol, Sociologia da Homossexualidade, Dança e Expressão Artística, além de um curso para formação de drag queens.

A escola E-JOVEM foi criada como uma forma de extirpar a homofobia (que engloba um rol de preconceitos e violências sofridas pela população homossexual) e de promover uma socialização diferenciada, e se constituiu a fim de provocar mudanças na realidade social, no que tange às vivências das sexualidades.

Sendo uma escola de ensino técnico, a escola E-JOVEM tem em seu projeto pedagógico matérias diferenciadas para envolver o público atendido, sendo as de Expressão Cultural Multimídia divididas em três áreas a serem desenvolvidas e aprofundadas ao longo de três anos; são elas: Expressão Artística (Dança - ano 1, Música - ano 2 e Performance (Drag Queen) - ano 3), Expressão Cênica (WEB TV ano 1, Teatro - ano 2, Cinema - ano 3) e Expressão Gráfica (Fanzine - ano 1, Revista ano 2 e Livro - ano 3), tendo como objetivo dos cursos a circulação no estado de São Paulo do material produzido pelos alunos, tais como, CDs, DVDs, livros, revistas, peças de teatro e espetáculos de drag queens.

Em janeiro de 2010, após a autorização do MEC e com o repasse de verba do Ministério da Cultura (MINC), foram abertas as inscrições para os cursos oferecidos pela escola E-JOVEM, sendo aceitos prioritariamente interessados com idade entre 12 a 18 anos (outras faixas de idade eram aceitas se houvessem vagas remanescentes). As inscrições desde o início foram abertas também ao público heterossexual, aceitando os simpatizantes do público LGBTTT como ingressantes no ensino técnico da escola. 
O principal objetivo da E-JOVEM é oferecer ao jovem todas as ferramentas para que ele possa se expressar, conhecer a Cultura LGBTTT e produzir sua própria cultura, propondo uma socialização diferenciada.

$\mathrm{O}$ uso das Tecnologias educacionais, no caso da E-JOVEM, constituiu uma importante ferramenta nesse processo, visto o grande interesse dos jovens por essas ferramentas, na medida em que torna o ambiente educacional bem mais dinâmico e participativo, pois é algo que faz parte do universo dos jovens na atualidade, se afigurando como um dos traços identitários dessa juventude.

Tal artigo tem como principal objetivo refletir e discutir sobre a existência do preconceito contra os homossexuais, se utilizando das novas tecnologias como importante instrumento no combate ao preconceito, para que a partir daí, possa se encontrar mecanismos que possibilitem a construção de uma escola para todos, sendo esse o pressuposto fundamental de uma sociedade justa e igualitária

Os dados obtidos deram luz sobre os problemas essenciais da natureza e funcionamento da cultura e do comportamento social humano.

\section{Abordagem teórico-metodológica}

Este trabalho insere-se em uma leitura interdisciplinar, coletando metodologias e teorias para dar conta do trabalho envolvido na produção e elaboração das políticas de combate à homofobia, como proposto pelo próprio MEC. Neste trabalho coube estudar um caso (E-JOVEM) e refletir sobre os avanços e dificuldades na implementação de políticas públicas de combate à homofobia. Tais observações foram realizadas via diário de campo.

\section{A vida na e-jovem em um diário de campo: resultados das observações participantes}

A filosofia desta pesquisa etnográfica repousa na doutrina que compreende a vida e a existência social como localizadas e resultantes no fato mais óbvio: o encontro e o relacionamento. E é nesse e desse encontro que emergem todas as formas de negociação, solidariedade, valores, redes, transmissão, trocas, simbologias e cerimônias, 
conflitos, compartilhamentos, etc, entre o grupo discente e docente da E-JOVEM. O ambiente físico da escola é de uma casa simples e "familiar", já que o local onde os alunos estudam também é a moradia da diretora e do fundador da E-JOVEM. Como pesquisador, passei trintas horas observando os alunos, professores, direção e de familiares que lá deixavam seus filhos. No início tive o estranhamento linguístico após me ver rodeado de jovens utilizando gírias para se comunicarem, gírias como: mapoa (mulher), sapata (lésbica), dar a Elza (roubar), estar uó (ruim/feio), cuidado com a tia (cuidado com o HIV/AIDS), entre tantas outras. Com as observações e horas de participação no ambiente escolar da E-JOVEM, pude reproduzir um diário de campo, embasado principalmente nas aulas de Fanzine.

A pesquisa etnográfica apresenta e traduz a prática da observação, da descrição e da análise das dinâmicas interativas e comunicativas como uma das mais relevantes técnicas. Assim, ao entrar na E-JOVEM, participamos de encontros e grupos de trabalhos, totalizando trinta horas no ambiente escolar pesquisado. Ambiente este localizado na casa do fundador e diretor da escola, um casal homossexual, juntos a mais de dez anos. Gritaria, música alta, adolescentes, sanduíches de presunto e queijo, bolo de cenoura, suco de caixinha, perucas e sapatos de salto alto. Era a hora do recreio, intervalo entre a Aula de Dança e a Aula de Produção de Fanzines, na E-JOVEM em Campinas. Depois todos entravam na sala de aula, com pilhas de revistas, caixas com canetinhas coloridas e lápis de cor, tesouras, tubos de cola, computadores... mais perucas e sapatos de salto alto. Assim começavam as oficinas de produção de fanzines com adolescentes e jovens gays, lésbicas, bissexuais, transexuais, travestis, transgêneros e héteros - também chamado de LGBTTTeens ${ }^{2}$ ou e-jovens.

Este Ponto de Cultura é extensão da escola E-JOVEM de Adolescentes Gays, Lésbicas e Aliados, fundada por Deco Ribeiro em 2001. A escola é administrada conjuntamente com a esposa, a drag Lohren Beauty, ou Chesller Moreira. A proposta da Escola Jovem LGBTTT é de sanar com a homofobia e divulgar as produções criadas por homossexuais, principalmente após os anos 1960, quando LGBTTTs começaram a ser mais expressivos e a se projetar para fora dos guetos. Muitas dessas expressões aconteciam em grupos isolados e escondidos, reuniões que davam espaço a performances artísticas e debates. Alguns desses grupos de homossexuais produziam informativos, revistinhas mimeografadas, fanzines, que circulavam como forma de

${ }^{2}$ LGBTTT (Lésbicas, Gays, Bissexuais e Travestis). Teen é a abreviação de teenager, que em inglês significa adolescente. 
comunicação, sociabilização e troca de ideias entre indivíduos que compartilhavam os mesmos interesses e identidades. Muitos desses meios impressos eram produtos de um estado repressivo, com discursos politizados, apelo emocional e tentativa de conscientização sobre os problemas sociais e preconceitos que sofriam. Mas nem tudo o que era criado e trocado naqueles grupos, naquelas épocas, atingia outras esferas sociais.

Outro objetivo da Escola Jovem LGBTTT é incentivar novos trabalhos e criações, por isso oferece cursos ligados a produtos que possam ser distribuídos para a comunidade, como espetáculos de dança, vídeos para internet e fanzines.

As aulas de produção de fanzines integram o primeiro módulo do Curso de Expressão Gráfica e se estende por cerca de 8 meses. O objetivo das aulas é passar noções de semiótica, teorias da comunicação, história das mídias alternativas, debater temas ligados à diversidade sexual, e preparar os alunos para os módulos seguintes, de Produção de Revista e depois a produção de um Livro-reportagem.

Fanzines são produções caseiras, artesanais, de baixo custo, feitas individualmente ou em grupo, a fim de divulgar pensamentos e expor debates. Por isso fanzines são muito utilizados por grupos de militância, feministas, veganos, ecologistas, artistas que querem divulgar trabalhos, fotografias, poemas, contos, performances. $\mathrm{O}$ termo "fanzine" surgiu da junção entre as palavras "FANatic" e "magaZINE", ou seja, revistas feitas por fãs de determinado assunto, com tema bem definido, mas sem um público-alvo tão específico.

O público que procurava o curso de Produção de Fanzines era bem jovem: Max, 14 anos; Hosana, 15; Nillo, 16; Vinicius/Saivetty, 16; Dani, 17; Michael/Shane, 17; Dell, 18; Juana Camp, 18; Lene, 18; Bruna Baby, 19 e Aline, $29^{3}$.No primeiro dia os jovens conheceram a Escola e logo depois começamos uma conversa a fim de nos conhecermos. Durante a conversa cada aluno contou um pouco sobre sua vida. Alguns eram homossexuais assumidos, outros não, alguns héteros. Contaram casos de violência doméstica, agressão, tentativas de suicídio. Havia diversidade de interesses e expectativas sobre o curso: desde curiosidade em relação às artes gráficas ou participação da militância e debates sobre diversidade, até garotos que procuravam outros gays com interesses além de sexo e balada, "pois na internet e nas boates só tem isso". 
Na primeira aula tentei me afastar do papel de pesquisador na apresentação perante os alunos (ainda não sabia como os jovens lidavam com o termo "pesquisador" e se essa palavra carregava alguma essência repressora), portanto, ao me apresentar, disse que fazer fanzines era um passatempo para mim, e por meio desse passatempo eu me expressava, assim como milhares de outras pessoas o fazem. Quis mostrar interesse em participar do grupo como um fanzineiro observador, e, dessa forma, tive que aprender o que era aquilo, para me expressar diante de olhares curiosos. Expliquei para eles que não existem regras em um fanzine, é a liberdade de expressão colocada no papel, o foco não é no público consumidor, e sim no próprio fanzineiro. Durante as primeiras aulas os jovens perguntavam para o professor: Posso escrever palavrão? Posso fazer direto no computador? Posso colar lasquinhas de lápis de cor? Posso dizer que meu pai é um banana? Poucos encontros depois e eles foram deixando de perguntar o que podiam ou não fazer, e o processo de confecção de suas páginas fluía sem qualquer intervenção, com raras exceções.

A "repressão" e a "necessidade de visibilização" estão presentes já no nome escolhido para o fanzine, durante os primeiros encontros. São cinco significados: 1 "No Closet", ou seja, "No armário". O armário é uma gíria e significa esconderijo, portanto, quando um gay "está no armário" é porque ele não é assumido e está escondido; 2 - "No Closet", ou "Sem armário" em inglês, significando uma negação à repressão, uma luta; 3 - "No Close!”, em que o T dá lugar a um ponto de exclamação. Quando o curso começou, era muito usada a gíria "dar close" e "estar no close", com os mesmos sentidos de "dar pinta", "dar bandeira", ou seja, "ficar evidente, à mostra, nítido, focado, aproximado". Era usado em tom de elogio, portando era ótimo estar "no close!"; 4 - "No Close!", "Sem destaque” em inglês, com a negação implícita e significando "sem brilho, sem evidência, sem expressão"; 5 - "No Close!" derivando de "not close" ("não feche" em inglês), com o "fechar" evidentemente significando "reprimir" ou "invisibilizar".

O combinado entre eles, alunos e professor, era de fazer cinco edições de fanzines com os seguintes temas: 1 - Sigla LGBTTT e Identidades; 2 - Infância e Diversidade Sexual; 3 - Segurança e Saúde Pública; 4 - As Cores da Bandeira; 5 "Revolta de Stonewall”, marco do início da luta pela diversidade sexual.

Percebi que nos primeiros encontros os LGBTTTeens preferiam trabalhar individualmente e sentiam a necessidade de explicar as próprias composições, justificar os elementos que as compunham e, por meio disso, acabavam fazendo uma espécie de 
terapia em grupo. Mais tarde, algumas páginas começaram a passar por um processo coletivo, todos participando de várias páginas ao mesmo tempo, opinando, procurando materiais, e ao final do processo, a página estava carregada de sentido para todos. Antes, o processo era algo individual, que explodia na necessidade em expor algo que estava contido e que eles queriam dizer para a sociedade. Depois se tornou uma maneira de se expressar com o objetivo secundário de educar e divulgar suas produções. Ao final, criamos o fanzine sobre a Revolta de Stonewall, em que os fatos históricos estão em primeiro plano em relação aos discursos reprimidos.

A leitura de "O Processo Ritual" - os trechos sobre liminaridades, communitas e os rituais modernos das performances artísticas - me provocou a reflexão sobre uma dinâmica dos encontros, que já havia sido identificada, mas nunca ficou tão nítida. Alguns jovens participavam da aula de dança, das 09h00 às 12h00, aos sábados, e faziam um lanche oferecido pelo própria E-JOVEM (feito por Lohren - esposa de Deco). As aulas de fanzine aconteciam das $13 \mathrm{~h} 00$ às $16 \mathrm{~h} 00$. Os primeiros minutos eram mais agitados, mais gritaria do que conversa. Em pouco menos de uma hora o silêncio dominava, quebrado pelo barulho de tesouras, pelas revistas sendo folheadas, pelas conversas quase sussurradas. Às vezes, durante o intervalo, eram selecionados clipes e músicas para serem ouvidas durante a aula.

Os administradores da E-JOVEM diziam ficar impressionados com o silêncio e a concentração, pois nos outros cursos os LGBTTTeens faziam mais bagunça. Alguns visitantes (dois alunos de Comunicação da PUC - CAMPINAS), também comentavam ser algo muito inusitado, por exemplo, ver as revistas sendo vasculhadas - e muitas vezes lidas e comentadas - por adolescentes que minutos atrás haviam dito ter desistido dos estudos (caso de Max, 14, e Vinícius/Saraivetty - nome como drag ${ }^{4}, 16$ ); ou ver outros dois adolescentes que quase se agrediram minutos antes numa discussão acalorada sobre duas cantoras pop, agora fazendo uma pesquisa sobre "troca-troca", de maneira séria, mostrando a gravidade que aquele assunto tinha para eles, procurando até mesmo pesquisas científicas sobre as relações na infância.

${ }^{4}$ O termo dragqueen é uma gíria que surgiu por volta de 1980 , tanto no mundo gay quanto no teatro. Dragqueens são artistas performáticos que se travestem, fantasiando-se cômica ou exageradamente com o intuito geralmente profissional artístico. Na maioria das vezes, apresentam-se em boates e bares LGBTTT, embora haja drags que façam eventos para público misto e heterossexuais, como animação em festas de casamento, debutantes, formaturas etc. Portanto, chama-se dragqueen o homem que se veste com roupas exageradas e, muitas vezes com estilo andrógino, femininas estilizadas e que tem como principal característica o humor. 
A qualquer momento, quando algumas páginas já estavam prontas, começava a troca de experiências, cada um à sua maneira: alguns explicavam seu trabalho detalhadamente; outros pediam por interpretações, que geravam ótimos debates; outros diziam que a página ainda não estava pronta e pediam sugestões e críticas (e alguns ficavam visivelmente chateados ou bravos ao receberem as críticas que haviam pedido).

As liminaridades eram marcantes no grupo: criança ou adulto; feminino ou masculino; assumido ou enrustido; dependente ou independente. A "Homofobia ou nãohomofobia" era também algo visto como uma situação liminar, de acordo com uma explicação de Nilo e Lene, sobre a contracapa do fanzine Número 1, sobre a sigla LGBTTT:

Existem héteros que não amam nem odeiam gays, porque ninguém nasce odiando as coisas. E existem os héteros que aprendem a ser homofóbicos, que a gente mostrou lá na página três. Um dos objetivos do 'No Closet!' é educar esses homofóbicos e tirar eles dessa situação, transformando eles em héteros neutros de novo ou em aliados (NILO).

Aqui na Escola aprendemos essa palavra, que é 'aliados', héteros que lutam contra a homofobia. Usamos essa página para falar sobre a diversidade e sobre os homofóbicos que batem até nas pessoas que não são gays e lésbicas. Eu sou uma hétero aliada e justamente por sofrer homofobia eu vim aqui pra Escola (LENE).

Algo que era bastante evidente é que os LGBTTTeens se sentiam orgulhosos ao final de várias composições, mesmo quando compartilhada de maneira tímida, mas não forçada, pois a apresentação das páginas era uma atividade opcional e muitas delas não eram compartilhadas. Era como uma passagem para outro estado ou pelo menos a experiência de uma nova sensação. Como se eles e elas deixassem de serem crianças sem opinião e se tornassem pessoas capazes de realizar discursos e expor pensamentos. "É igual fazer um trabalho da escola, mas a gente pode realmente dizer alguma coisa, porque na escola a gente só diz o que o professor quer" (HOSANA).

Era a passagem de "alunos em aprendizagem" para "educadores e comunicadores", e muitos afirmavam constantemente essa opressão exercida pelos adultos que insistiam em tratá-los com pessoas sem nada a comunicar.

Mas nem tudo o que foi produzido pôde ser publicado, pois existe um limite de impressão que dependia do orçamento feito pela E-JOVEM. Muitas dessas páginas foram feitas apenas para desabafar e os próprios autores pediam para não serem publicadas. Algumas páginas foram guardadas, outras foram rasgadas por eles. 
Max, 14 anos, tinha uma relação ruim com a mãe e a avó materna e expressou isso durante a aula:

Tudo o que eu falo está errado! Tudo eu não sei! Pra tudo eu sou novo demais. Eu não posso fazer nada, pois tudo o que eu faço está errado. Daí eu sou gay, e sou errado também porque eu sou gay. (MAX)

Frequentemente rasgava suas páginas, nem chegava a mostrar para os outros alunos. Ele era o mais agitado do grupo, o que falava mais alto, mais dava risadas, mais bagunçava, mas ficava visivelmente desconfortável ao trocar suas páginas e sentimentos com o grupo.

Antes de apresentar a página para a turma, ele pedia pra mostrar antes para o professor ou para o Deco, diretor do E-JOVEM. Acredito que ele tivesse medo de ser de alguma maneira avaliado negativamente pelo outros LGBTTTeens, seus pares. Suas páginas eram muito criativas, caprichadas e suas explicações bastante complexas. Ele trabalhava em alguma página, às vezes por mais de um dia, e depois rasgava, algumas vezes sem mostrar para os que sempre mostrava. Ele era o que mais perguntava sobre os limites da sua expressão - limites que todos já tinham percebido que não existiam durante as aulas. Mas a facilidade que ele tinha em dividir as páginas com o professor de fanzine não era a mesma que ele tinha ao dividir com o grupo. Enquanto integrante da sociedade, e daquele grupo, ele era extrovertido e chamava atenção para si, mas sua individualidade era fechada em si mesma, silenciada por razões que não identifiquei. Conclui que ele estava tão acostumado a ter sua expressão reprimida, que ele sentia necessidade de alguém que o dirigisse e o deixasse seguro para se expressar.

Hosana, 15 anos, era o oposto de Max e gostava de mostrar suas páginas. Ela era uma das alunas mais curiosas, estimulava debates de maneira muito carismática.

\footnotetext{
Ai, eu sou uma burra! Antes de entrar aqui, pra mim travesti só fazia prostituição, e gay queria ser mulher, mas não era nem travesti nem mulher, era só gay que poderia virar travesti algum dia. Vai ver eu ainda não sei o que é gay e nem travesti, mas sei que não é o que eu achava que era. (HOSANA)
}

Aliás, esses estranhamentos como o de Hosana geravam debates e propostas de páginas. "Você é gay, mas não parece!" "Como você consegue ser tão delicada e tão lésbica?", "Existe travesti virgem?!", "Existe país com pena de morte para gays?!", 
E o que dá um caráter sui generis ao "No Closet!" é justamente isso: ser uma produção gráfica feita por adolescentes LGBTTTs, que compartilham fragmentos de suas vidas, sentindo-se completos e acolhidos, se estranhando, se conhecendo, se reconhecendo, se mostrando para uma sociedade que, em outras proporções e de outras maneiras, os estranha, conhecendo-os e reconhecendo-os, mas que despreza e constrange alguns fragmentos de suas totalidades, como suas configurações sexuais, por exemplo.

Esse constrangimento foi exemplificado por um comentário de Lene, sobre uma página de Vinicius/Saraivetty, em que há um homem de pé, com uma gota entre as pernas e uma poça d'água embaixo. Vários significados foram dados pelo grupo, entre eles, que aquilo era água residual de um processo de limpeza do reto (conhecida entre os gays como "Chuca"), ou então queria dizer que mesmo sendo gay ele "faz xixi em pé e não sentado como as mulheres", ou então era um "homem menstruando". Lene comentou:

Quando uma menina menstrua pela primeira vez, ela pode pedir ajuda para os pais. E os pais nos ensinam como fazer higiene, $e$ quando crescemos temos um pouco de liberdade para conversar sobre sexo, principalmente de filha para mãe, de filho para pai, ou entre irmãos ou amigos do mesmo sexo. Mas com quem um menino gay pode conversar? Eu não consigo imaginar um pai falando sobre chuca com um filho. Até poucos dias atrás eu não falaria sobre chuca nem com vocês! E se muita gente já não vê liberdade para falar sobre virgindade com os pais, imagina falar sobre perder a virgindade com alguém do mesmo sexo? (LENE)

Esses questionamentos originaram outras composições, sobre virgindade, sobre falta de diálogo, sobre a figura dos pais, sobre saúde. E esse era um processo que não acabava, pois a cada página eram temas novos que brotavam ou ressurgiam com uma nova perspectiva. Era um ciclo: exposição e partilha do trabalho, acolhimento, reconhecimento, estranhamento ou identificação com o trabalho pelos outros, criação de um novo trabalho motivado pelo trabalho exposto, exposição e partilha do novo trabalho.

Quem participou e ouviu as explicações daqueles trabalhos, pelos próprios fanzineiros, obviamente foi interpelado de maneira mais densa do que alguém que apenas folheou, mesmo que atentamente, os fanzines. Tiveram contato com a justificativa da escolha dos elementos e recursos e, por vezes, influenciaram que a página se configurasse daquela maneira. Mesmo assim, algumas páginas chamam a 
atenção de qualquer pessoa, sem a necessidade de uma mediação, como, por exemplo, no Fanzine 2, sobre "Infância e Diversidade Sexual", em que o personagem da história em quadrinhos das páginas 4 e 5, um menino de 6 anos, é proibido de fazer um piquenique amoroso com o namoradinho e sente-se jogado para os jacarés pela professora. Ao final, o personagem diz: "Na hora que a nossa felicidade está em jogo, não podemos brincar”. Essa frase, de uma composição feita por Vinícius/Saraivetty, mexeu com todos os alunos e eles concluíram que desde pequenos eles tinham que fingir estar felizes e brincar com o que não queriam, ou ser quem não queriam. Eles falavam dos papéis sexistas nas brincadeiras infantis. Foi nessa partilha que um dos alunos lembrou de Ludovic, personagem do filme "MaVie Em Rose", que se veste de Branca de Neve durante uma peça da escolinha para realizar, mesmo que ilusoriamente, a vontade que tinha em ter um papel social feminino. E então resolveram fazer uma seleção de filmes que tratasse de sexualidade e infância. A pesquisa por filmes e leitura de sinopses estimulou a discussão de novas pautas, como incesto, troca-troca, profissões e estereótipos.

Essas discussões sobre a divisão de papéis sexuais era constante e Hosana se maravilhava com o que chamava de "novas descobertas". O que tanto fascinava Hosana eram os papéis sócios sexuais que eram esvaziados ou subvertidos pelos gays daquele grupo. Ela adorava ver alguns meninos se transformando em drags e dizia ter inveja da vida dos meninos gays, pois "podem se vestir de mulher, dar mais close que eu e ainda por cima fazer xixi em pé em qualquer murinho!”. Essas observações de Hosana foram condensadas diversas vezes, como nas páginas 6 e 7 do Fanzine 2, em que ela propõe jogos e uma escola sem divisões de gêneros sexuais, com pessoas diferentes fazendo as mesmas atividades juntos, sem imposições ou divisões.

A página 10 da mesma edição também foi feita por Hosana. Em mais um de seus estranhamentos, Hosana dizia que ao passo que os meninos têm mais liberdade para correr, se sujar, falar palavrões, se rebelar, ser violentos, eles também estão presos, pois não podem brincar com coisas mais delicadas, como bonecas, mesmo que seja a boneca da She-ra ou algo que remeta a um universo truculento. Apontar essas oposições era constante para Hosana e na sua visão as divisões de gênero sexuais nas interações infantis eram banais e naturais, pois desde pequena ela teve contato com a frase "isso é de menino, isso é de menina”. Mas foi fazendo essa página que ela, junto com o grupo, foi significando os elementos até então banais: A bola era chutada, era mandada pra longe, era alvo de um movimento violento, furioso; em oposição às bonecas que eram 
carregadas próximas ao peito; Os meninos podem usar máscaras, se sujar mais, ficar feios, gritar, ter brincadeiras até mesmo escatológicas e assustadoras, em oposição às meninas que brincam de se maquiar, fazer tranças, e aprendem a cultuar a beleza delas.

Na página 12, a frase "Ser livre para ser criança" é completada por "não tem price (preço)", e desmentida pela frase "Mas tem máfia". No caso, a máfia adulta sexista, que proíbe um menino de brincar com uma boneca do mesmo jeito que uma menina.

É uma liberdade, mas não é, porque um menino pode brincar de boneca se fingir que está salvando a she-ra, ou fazer lutinha com ela, mas ele não pode brincar com uma Barbie que não está sendo salva ou que não está lutando. (HOSANA)

Fazendo uma comparação superficial com o texto "O Arco e o Cesto", , onde a boneca é o cesto, a bola é o arco, os homens caçam e chutam, as mulheres carregam e cuidam. Antes de nascer o menino ou menina já recebe o nome masculino ou feminino, os pais traçam planos de vida de acordo com o gênero sexual, são dadas várias insígnias de acordo com o gênero sexual. E se desenvolvem até a fase adulta nessa divisão de papéis.

A bola que o menino chutava, as guerrinhas que ele fazia, transformam-se na rivalidade contra outros meninos e no perfume masculino para conquistar a primeira namorada, e como diz o texto, "alguns anos mais tarde, oferecem-lhe um arco muito maior, flechas já eficazes, e os pássaros que ele traz para sua mãe são a prova de que ele é um rapaz sério e a promessa de que será um bom caçador”. Depois vêm as figuras modernas do primeiro emprego, primeira bebida alcoólica, primeira balada, primeira vez a dirigir um carro de verdade, primeira relação sexual, que tornam o rapaz um "verdadeiro caçador, um kybuchuété6". Essas expectativas depositadas nos filhos era algo que mexia com os LGBTTTeens. Muitos deles diziam não ter medo dos pais ao assumir a homossexualidade, mas alegavam que ficavam com receio de desapontá-los.

E esses debates quase sempre eram levantados pela Hosana e pela Dani, heterossexuais vaidosas e delicadas, as bonequinhas da Escola. Os gays gostavam muito de ouvi-las, e acredito que a heterossexualidade delas é que tenha garantido o interesse deles, pois eles já haviam banalizado essa discussão das insígnias sexuais. Já tinham

\footnotetext{
5 “A sociedade contra o Estado de 1986, do autor Pierre Clastres.

${ }^{6}$ Termo utilizado por Pierre Clastres no livro "A sociedade contra o Estado”, 1986. Kybuchuété significa verdadeiro caçador, guerreiro.
} 
aprendido a lidar com isso. Uma conversa entre eles, meninos gays, que haviam passado pelos mesmos constrangimentos, era diferente quando defendido por uma menina, hétero, com uma família sem preconceitos explícitos, pois o pai de Hosana deixava a filha na porta da escola.

Acontecendo essa conjunção, o "Pané" ou "azar na caça” é atraído. Essa "maldição" é vista por muitos pais ao verem o filho se interessando por atividades classificadas femininas, ou o contrário. Os pais temem a homossexualidade no filho, entre muitos motivos, pois eles temem que o filho e a família deixem de ser vistos como célula da comunidade a que pertence. A homossexualidade ainda é considerada inútil para a reprodução, portanto, a união homossexual não gera uma nova família, não gera novos consumidores, não gera padrões de caça, coleta e nem troca de bens. Ainda é forte o argumento de que um filho homossexual destrói a estrutura social e danifica a economia. $\mathrm{O}$ casamento e a família legitimam o estado da estrutura e um filho gay não garantiria a solidez dessa estrutura, por isso é indesejável.

Muitos adolescentes acreditam nisso e isso dá inspiração de sobra para a composição de suas páginas. Alguns têm medo da estrutura social, como ficou evidente no Fanzine 3, sobre Segurança e Saúde Pública; outros se sentem fora da estrutura, como nas páginas 8 e 9 do Fanzine 2, no qual a realidade é como se fosse a tela de uma $\mathrm{TV}$, com a frase "Eu de fora" frisando essa posição; alguns se sentem vazios e invisíveis diante da estrutura, como na capa do Fanzine 2, em que um boneco assexual é bombardeado por vários elementos:

O boneco unissex no caos da capa é como as crianças, que são bonecos neutros que os pais usam pra brincar, mas brincam errado, porque os pais deles também brincaram errado. (Vinicius/Saraivetty).

Essas divisões de papéis foram trabalhadas em diversos temas, como sobre o Alistamento Militar Obrigatório, a presença de mulheres e homens homossexuais na Segurança Pública, como se estes não tivessem habilidade para lidar com essa atividade. E, até entre os LGBTTTeens, é comum imaginar que uma mulher ou gay teriam funções menos arriscadas nas Forças Armadas, o que me lembrou o trecho em que se diz que um Guaiaqui que atraíra o Pané e não podia mais usar o arco, podia capturar tatus e quatis com as mãos, tipo de caça que está longe de apresentar a mesma dignidade que a caça com arco. Um gay ou mulher num posto alto de comando militar, ou um homem heterossexual que não demonstra interesse na segurança e disciplina da sociedade, 
introduzem um fator de desordem que, de tão indesejável, provocam em alguns a homofobia e o machismo que se manifestam por meio de piadas, violência verbal e física; e, no caso destes LGBTTTeens, provocam as tensões, angústias e anseios que se manifestam por meio das composições das páginas.

Acredito que compor páginas de um fanzine, que muitas vezes fazem sentido apenas para o próprio fanzineiro, assim como o canto dos caçadores Guaiaqui, manifestam a função aberta de comunicação e também funcionam como constituição de um Ego. Como a intenção da Escola Jovem LGBTTT é a divulgação de produções culturais, escolheram publicar páginas que além de mostrar temas frequentes sobre diversidade sexual, também mostrassem um pouco desses adolescentes. Algumas páginas eram tão carregadas de emoções pessoais que se tornaram abstratas e, por não atingir o receptor, não foram impressas. Mas podem ser vistas na sede da Escola. Algumas páginas não foram publicadas a fim de manter o caráter social do Ponto de Cultura e de divulgar material que objetivasse a militância LGBTTT e a visibilização de assuntos pouco discutidos fora dos grupos de homossexuais.

Participar daqueles encontros causou um impacto muito grande em mim e nos alunos. Eu tinha meus círculos sociais, eles tinham os deles, mas quando eles começavam a justificar suas composições, era praticamente uma purificação. Como, por exemplo, o pedido de Max de colocar uma abóbora em uma das páginas. Sua explicação:

“Eu não era uma criança, eu era uma abóbora querendo ser princesa. Eu era um gato feio, mas posso virar uma gata linda num estalar de dedos”.

\section{E esse pacote de "Luftal MAX”?}

"Porque meu nome é Max e estou pronto pra explodir".

Atualmente, os fanzines "No Closet!" são trocados com outros grupos de fanzineiros ou em eventos sobre diversidade sexual, e são sempre recebidos com muita curiosidade e admiração. Mas as páginas impressas dessas revistinhas artesanais não carregam nem metade das histórias, angústias e alegrias que foram o combustível para a criação. Foi inevitável não fazer um paralelo com o artigo "Palavra (en)cantada, palavra encorpada" (Morelli, 2010), sobre "o tipo de interação social sui generis que torna possível a criação." Ao final de vários encontros (cinco que participei) senti um nó na garganta ao perceber que muitos daqueles alunos, outrora tão expressivos, alegres e sentindo-se seres integrais e integrados, retornariam para suas casas, onde teriam que se 
adequar a uma estrutura, seguir regras, obedecer a sexismos, viver um fragmento desagradável da vida e voltar para dentro dos armários, calados, para no próximo final de semana saírem do armário no "No Closet!".

\section{Considerações finais}

Deixar de reconhecer e legitimar a existência digna dos LGBTTTs nesta nação é perpetuar um histórico de violência e preconceito frente a este público; é manter a nação estagnada no tempo, desrespeitando o povo que aqui nasceu ou que escolheu o Brasil como território para moradia e desenvolvimento.

Conclui-se que a E-JOVEM proporciona aos alunos momentos de libertação diante da opressão vivida por cada um; pode se verificar, nas falas dos entrevistados, que o preconceito que ainda existe contra pessoas que vão por caminhos inversos do que a sociedade coloca como padrão, e é forte e preocupante. Ao se ter momentos de afetividade e de abertura diante das falas e da preocupação daqueles que sofrem, a EJOVEM passa para seus alunos e a comunidade o sentido da liberdade diante da aceitação de suas orientações sexuais, sem medo de represálias, mesmo que isso pareça existir somente no espaço escolar da E-JOVEM.

A implementação dos programas de políticas públicas contra a homofobia vem atender dispositivo constitucional e garantia suprema dos direitos humanos, objetivando ações proativas dos organismos de segurança pública no combate aos crimes de intolerância, assim como promover no seio da sociedade a cultura da tolerância e respeito às diferenças. Não se concebe que à luz do estado democrático de direito ainda existam sociedades que pratiquem, fomentem ou se omitam em relação aos crimes de ódio que vêm dizimando membros de sua sociedade, relegando-lhes a um segundo plano, empurrando-os para um armário sombrio onde muitos vivem durante toda a vida com medo da discriminação, privados do maior de todos os direitos dados ao ser humano: a felicidade. Apesar de termos já políticas públicas orientadas para este fim, o resultado em termos de diminuição da violência contra a população LGBTTT ainda é insatisfatório no Brasil. É necessário avaliar a eficácia das políticas públicas já em andamento, como é o caso deste estudo, mas também implementar novas políticas que contribuam com a mudança de mentalidade da população. 


\section{REFERÊNCIAS}

BORRILLO, D. Homofobia. Espanha: Bellaterra, 2001.

EVANS-PRITCHARD, E. E. Os nuer: uma descrição do modo de subsistência e das instituições políticas de um povo nilota. São Paulo: Perspectiva, 2007.

LE GOFF, J. História e memória. Campinas: Editora UNICAMP, 1990.

PORTELLI, A. A filosofia e os fatos: narração, interpretação e significado nas memórias e nas fontes orais. Tempo, Universidade Federal Fluminense, v. 1, n. 2, 1996, p. 59-7.

MAUSS, M. Manual de etnografia. Lisboa: Dom Quixote, 1993.

SCHULMAN, S. Ties that bind: Familial Homophobia and its Consequences. New York: The New, 2009.

TIN, L. G. (Org). The Dictionary of homophobia. Vancouver: Arsenal Pulp Press, 2008.

WELZER-LANG, D. A construção do masculino: dominação das mulheres e homofobia. Revista Estudos Feministas, v. 9, n. 2, Florianópolis, 2001.

\section{Como referenciar este artigo}

SILVA, Renan Antônio. Ensino, tecnologia e preconceito: diário de campo em uma escola destinada ao público LGBTTT no Brasil. Revista Ibero-Americana de Estudos em Educação, Araraquara, v. 12, n. esp. 2, p. 1217-1233, ago./2017. Disponível em: <http://dx.doi.org/10.21723/riaee.v12.n.esp.2.10291>. E-ISSN: 1982-5587.

Submetido em: 10/05/2017

Aprovado em: 28/07/2017 